\title{
ARTIGO
}

dol https://doi.org/10.22481/praxisedu.v16i41.7264

\section{A GAMIFICAÇÃO E OS DISPOSITIVOS DIGITAIS NO ENSINO SECUNDÁRIO EM BRAGA, PORTUGAL}

\author{
THE USE OF GAMIFICATION AND DIGITAL DEVICES IN SECONDARY \\ EDUCATION IN BRAGA, PORTUGAL
}

\section{EL USO DE GAMIFICACIÓN Y DISPOSITIVOS DIGITALES EN LA EDUCACIÓN SECUNDARIA EN BRAGA, PORTUGAL}

Gilson Pereira dos Santos Júnior

Instituto Federal de Sergipe - Brasil

Paula Escudeiro

Instituto Politécnico do Porto - Portugal

Adelina Moura

Escola Secundária Carlos Amarante - Portugal

Simone Lucena

Universidade Federal de Sergipe - Brasil

\begin{abstract}
Resumo: Na contemporaneidade os alunos que vivenciam as culturas digitais estão acostumados ao ciberespaço, a instantaneidade das redes sociais, a ludicidade dos jogos digitais e a busca por informação na Internet. No entanto, na sala de aula percebe-se a falta de motivação e de engajamento dos alunos, especialmente pela ausência de práticas pedagógicas em contextos digitais. Neste sentido, o artigo tem como propósito apresentar pistas de como a gamificação e os dispositivos digitais proporcionam a imersão das culturas digitais na sala de aula. De natureza qualitativa, o estudo analisou entrevistas realizadas com alunos que vivenciaram o uso da gamificação e dos dispositivos digitais nas aulas de Português de uma escola pública de ensino secundário em Portugal. Os relatos dos sujeitos demonstraram que os dispositivos utilizados favoreceram a interação e a comunicação entre professoraluno-aluno, proporcionaram o envolvimento dos alunos nas atividades e contribuíram para a inovação, a criatividade e o trabalho em equipe.
\end{abstract}

Palavras-chave: Aprendizagem inovadora. Culturas digitais. Gamificação.

Abstract: Actually, students who experience digital cultures are used to cyberspace, the immediacy of social networks, the playfulness of digital games and the search for information on the Internet. However, students lack motivation and engagement in the classroom, especially due to the absence of pedagogical practices in digital contexts. In this sense, the article aims to present clues on how 
gamification and digital devices provide the immersion of digital cultures in the classroom. Qualitative, the study analyzed interviews with students who experienced the use of gamification and digital devices in Portuguese classes of a public secondary school in Portugal. The subjects 'reports showed that the devices used favored the interaction and communication between teacher-student-student, provided the students' involvement in the activities and contributed to innovation, creativity and teamwork.

Keywords: Digital cultures. Gamification. Innovative learning.

Resumen: En los tiempos contemporáneos, los estudiantes que experimentan culturas digitales están acostumbradas al ciberespacio, la inmediatez de las redes sociales, la diversión de los juegos digitales y la búsqueda de información en Internet. Sin embargo, los estudiantes carecen de motivación y compromiso en el aula, especialmente debido a la ausencia de prácticas pedagógicas en contextos digitales. En este sentido, el artículo tiene como objetivo presentar pistas sobre cómo la gamificación y los dispositivos digitales proporcionan la inmersión de las culturas digitales en el aula. Cualitativamente, el estudio analizó entrevistas con estudiantes que experimentaron el uso de gamificación y dispositivos digitales en clases de portugués de una escuela secundaria pública en Portugal. Los informes de los sujetos mostraron que los dispositivos utilizados favorecieron la interacción y la comunicación entre profesor-alumno-alumno, proporcionaron la participación de los alumnos en las actividades y contribuyeron a la innovación, la creatividad y el trabajo en equipo.

Palabras clave: Aprendizaje innovador. Culturas digitales. Gamificación.

\section{Introdução}

Os jogos digitais estão presentes no cotidiano de jovens que, oriundos das culturas digitais, vivenciam a virtualidade e a ludicidade destes em busca de entretenimento, diversão, relacionamento e aprendizado. Estes jogos são considerados como um "objeto digital de uma cultura pós-moderna" (PETRY, 2016, p. 19) e proporcionam o relacionamento no ciberespaço, as experiências no mundo virtual e a aprendizagem por meio de regras, objetivos a serem alcançados, missões a serem cumpridas e decisões a serem tomadas. Prensky (2012, p. 156) apontou motivos que tornam os jogos atraentes, principalmente, para juventude:

Jogos são uma forma de diversão, o que nos proporciona prazer e satisfação; jogos são uma forma de brincar, o que faz nosso envolvimento ser intenso e fervoroso; jogos têm regras, o que nos dá estrutura; jogos têm metas, o que nos dá motivação; jogos são interativos, o que nos faz agir; jogos têm resultados e feedback, o que nos faz aprender; jogos são adaptáveis, o que nos faz seguir um fluxo; jogos têm vitórias, o que gratifica nosso ego; jogos têm conflitos, competições, desafios, oposições, o que nos dá adrenalina; jogos envolvem a solução de problemas, o que estimula nossa criatividade; jogos têm interação, o que nos leva a grupos sociais; jogos têm enredo e representações, o que nos proporciona emoção. (PRENSKY, 2012, p. 156). 
Muitos jovens não têm consciência disso, muitos pais não acreditam ou não querem acreditar nesta realidade, mas pesquisadores afirmam que eles aprendem enquanto se divertem navegando em um "estado de fluxo" (CSIKSZENTMIHALYI, 1988), no qual o tempo e o espaço se relativizam, conforme ressaltado por Alves (2014):

\begin{abstract}
Os nossos jovens passam muito tempo interagindo com os ambientes dos jogos eletrônicos e neles aprendem sobre história, mitologia, futebol, guerras, enfim uma infinidade de conteúdos mediados pelos jogos e passam mais horas jogando do que sentados nas salas de aulas, ouvindo os discursos dos professores. (ALVES, 2014, p. 101).
\end{abstract}

Não é à toa que a juventude contemporânea se comunica perfeitamente por redes sociais, preferem as imagens aos textos, realizam multitarefas simultaneamente com primazia e se acostumaram aos feedbacks e as recompensas imediatas e frequentes dos jogos digitais (PRENSKY, 2010, p. 60). A imersão dos indivíduos nas culturas digitais transformou-os em pessoas com particularidades que desafiam o modelo de escola atual estabelecido em outro contexto sócio-cultural-econômico e que ainda hoje é reproduzido por professores que "sabe pouco ou nada sobre o mundo digital de seus alunos" (PRENSKY, 2010, p. 38).

É importante destacar que o modelo de escola vigente, pautado nas ideias da modernidade, teve sua importância histórica na educação, entretanto, é perceptível que o modo de agir, pensar e interagir de alunos imersos nas culturas digitais difere de outrora, devido aos avanços e popularização das tecnologias digitais de informação e comunicação (TDIC). Hoje, a juventude busca "outros espaços, tempos ubíquos e multirreferenciais onde a construção do saber e o seu compartilhamento ocorrem de forma horizontal, sem a verticalidade do falar/ditar do professor em sala de aula" (LUCENA; OLIVEIRA; SANTOS JÚNIOR, 2017, p. 259), uma vez que as tecnologias modificaram suas formas de organizar os pensamentos e de pensar (SCHLEMMER; LOPES, 2016). Então, cabe a escola e seus atores sociais buscarem meios para atrair a atenção dos alunos, motivá-los a realizar atividades e recuperar o prazer do aprender no cotidiano destes jovens e uma das alternativas é se aproximar do universo lúdico e prazeroso dos jogos digitais por meio da gamificação na educação.

A gamificação é uso de mecânica, ideias e estética de jogos, em contextos de não jogos, com intuito de engajar pessoas, motivar ações, promover o aprendizado e solucionar problemas (KAPP, 2012). No âmbito educacional, a gamificação é considerada "uma readaptação da cultura lúdica às técnicas condicionantes da cibercultura" (MARTINS; GIRAFFA, 2015, p. 44) e comumente utilizada para atrair a atenção do aluno ao apresentar novos conceitos, estimulálo para executar atividades dentro e fora da sala de aula, motivá-lo a buscar informações e 
revisar os assuntos aprendidos, incentivá-lo a colaborar com os colegas na resolução de problemas e encorajá-lo a participar ativamente das aulas. Estes comportamentos são alcançados mediante o uso de elementos de jogos digitais como o feedback imediato e frequente, o reconhecimento social por meio de pontos, o uso de emblemas e de quadros de liderança, a liberdade de falhar, de reiniciar e de tentar novamente que, ao serem utilizados para gamificar atividades dentro e fora da escola, seja por meio de práticas pedagógicas ou uso de aplicações para dispositivos digitais, motivam e engajam os alunos em ações que os ajudam a atingir os objetivos pedagógicos definidos.

Embora os jovens estejam acostumados com as mecânicas, ideias e estéticas de jogos digitais, a visão reducionista do uso exclusivo de pontos, medalhas e quadro de liderança, "mecânicas simples, escaláveis, de baixo custo, facilmente implementadas" (SCHLEMMER, 2016, p. 115), deve ser evitado no processo de ensino-aprendizagem, pois podem induzir comportamentos e resultados indesejados ao promover competições em que "o outro é sempre, ou melhor, ou pior que você, nunca o diferente com quem se pode aprender" (SCHLEMMER, 2016, p. 115). Portanto, é essencial que os professores vivenciem os jogos digitais, compreendam as mecânicas, ideias e estéticas de jogos, conheçam as possibilidades, potenciais e limitações do uso da gamificação para ressignificar suas práticas pedagógicas visando aprimorar competências e habilidades nos alunos como a "[...] colaboração, cooperação, reflexão (pensamento crítico), autonomia, domínio de conteúdo, hábitos de estudo, limites, etc." (MARTINS; GIRAFFA, 2018, p.11) que serão primordiais para enfrentar um futuro em que o progresso exponencial, digital e combinatório das tecnologias digitais impactará na sociedade, na economia, no mercado de trabalho e nas relações de emprego (BRYNJOLFSSON; MCAFEE, 2015), frutos de desdobramentos da sociedade em rede preconizada por Castells (2002), que serão inevitáveis, pois, tudo muda e tudo evolui, as forças tecnológicas estão presentes e garantirão às mudanças porvir (KELLY, 2018).

$\mathrm{Na}$ busca por compreender como a gamificação e os dispositivos digitais podem estimular alunos com postura mais ativa no seu aprendizado, transformando-os atores e autores no processo, este artigo descreve pistas que emergiram de entrevistas com alunos da disciplina de Português ofertada pela Escola Secundária Carlos Amarante, situada em Braga, Portugal. A investigação foi realizada durante a mobilidade internacional acadêmica proporcionada pelo Instituto Federal de Sergipe por meio do Edital No 01/2018/REITORIA/IFS ${ }^{1}$ que, em parceria

\footnotetext{
${ }^{1}$ Edital No 01/2018/REITORIA/IFS - Internacionalização: estágio de Mobilidade Acadêmica em Portugal. Site: http://www.ifs.edu.br/propex/antigo/images/Retifica\%C3\%A7\%C3\%A3o_02_Edital_23_2018_MOBILIDADE_ PORTUGAL_FINAL.pdf
} 
com o Instituto Superior de Engenharia do Porto (ISEP) do Instituto Politécnico do Porto (IPP), tinha como principal objetivo "contribuir para o desenvolvimento científico, tecnológico e de inovação de forma bilateral, entre Portugal e Brasil”.

O restante do artigo está organizado de modo que, na seção 2, apresentamos o percurso metodológico da pesquisa, descrevendo o lócus, os sujeitos, a produção e a interpretação dos dados. A Seção 3, intitulada "Pistas Encontradas na Pesquisa", interpretamos as falas dos sujeitos da pesquisa, discutimos as pistas encontradas no percurso sobre a gamificação e os dispositivos digitais no ensino secundário em Portugal e dialogamos com pesquisadores das noções emergentes. Por fim, na seção 4, apresentamos a considerações finais deste trabalho.

\section{Percurso Metodológico da Pesquisa}

Trata-se de uma pesquisa exploratória e de abordagem qualitativa com intuito de compreender como a gamificação e os dispositivos digitais proporcionam a imersão das culturas digitais na sala de aula e possibilitam tornar os alunos atores ativos e responsáveis pelo seu aprendizado em uma escola do ensino secundário de Portugal.

O estudo foi realizado na Escola Secundária Carlos Amarante, situada em Braga, Portugal. Os sujeitos da pesquisa foram alunos do $10^{\circ}$ ao $11^{\circ}$ ano do Curso Profissional do Ensino Secundário com formação em Técnico de Programador de Informática oferecidos pela referida escola, que vivenciaram práticas pedagógicas com o uso da gamificação e dispositivos digitais na disciplina de Português por meio do projeto "Magos da Sabedoria", Moura (2019). A amostra de sujeitos foi selecionada por conveniência e constituída por alunos que aceitaram, voluntariamente, o convite para participar da entrevista durante o período da mobilidade internacional acadêmica.

"Magos da Sabedoria" é um projeto curricular de aprendizagem baseada em gamificação desenvolvido com alunos do $10^{\circ}$ ano da disciplina de Português cujo objetivo é "incrementar o rendimento acadêmico, fomentar o compromisso com o processo de aprendizagem, maior apropriação do uso de tecnologias digitais, aulas mais dinâmicas, promover o trabalho colaborativo, inovar e modernizar a educação" (MOURA, 2019, p. 72) por meio do estudo das obras "Os Lusíadas" e a "História Trágico-Marítima". A gamificação definida no projeto utiliza narrativas para motivar os alunos; missões, desafios, sistema de recompensas e pontuação para engajá-los; além do reconhecimento social por meio de cartas,

${ }^{2}$ O projeto "Magos da Sabedoria” está disponível em https://sites.google.com/view/magosabedoria/. 
emblemas, ranking e evolução de nível dos jogadores. Na Figura 1 está ilustrada a página inicial do projeto "Magos da Sabedoria".

Figura 1 - Página inicial do projeto "Magos da Sabedoria".

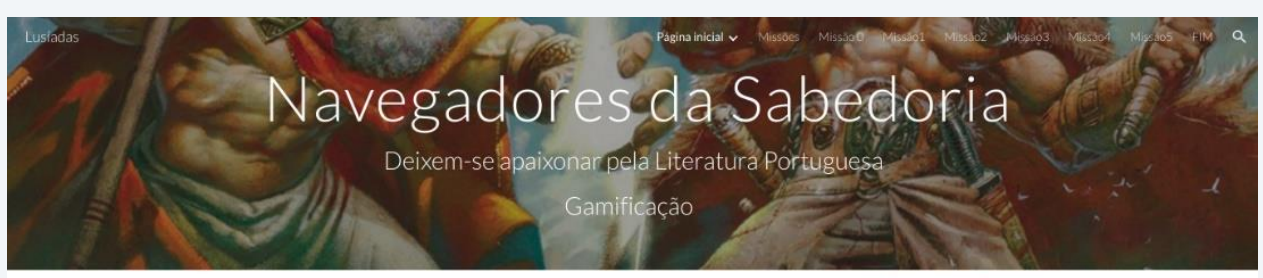

EPOPEIA DO PROFISSIONAL
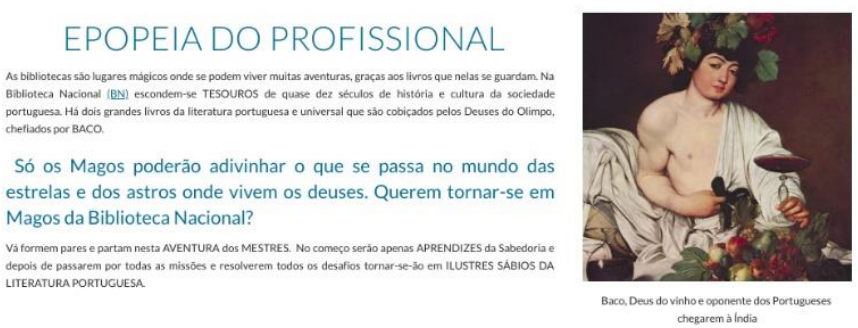

Fonte: Extraído da página do projeto "Magos da Sabedoria"3.

O curso Técnico de Programador de Informática da Escola Secundária Carlos Amarante tem como objetivo formar profissionais aptos a realizar atividades de concepção, especificação, projeto, implementação, avaliação, suporte e manutenção de sistemas informáticos e de tecnologias de processamento e transmissão de dados e informações e, portanto, está organizado em três pilares: Formação Sociocultural, que engloba o estudo de Português, Língua Estrangeira I e II, Área de Integração Tecnologia de Informação e Comunicação e Educação Física; Formação Científica, que aborda as disciplina de Matemática, Física e Química; e Formação Técnica, que discute sobre Arquitetura de Computadores, Sistemas Operativos, Redes da Comunicação, Programação e Sistemas de Informação e Formação em Contexto de Trabalho.

A escola dispõe de serviços de apoio ao estudo e à pesquisa bibliográfica orientada e recursos como áreas de trabalho individual, centro de recursos e equipamentos informáticos, laboratórios e oficinas, salas de informática e acesso à internet wireless aberto para favorecer o aprendizado. Tais serviços e os recursos possibilitam a gamificação e os dispositivos digitais na educação, dentro e fora da sala de aula.

A produção dos dados foi realizada por meio de entrevistas individuais, seguindo um roteiro $^{4}$ contendo questões para categorização do perfil do aluno e que abordavam a

\footnotetext{
${ }^{3}$ Disponível em https://sites.google.com/view/magosabedoria/.

${ }^{4}$ Roteiro de entrevista com alunos em Portugal disponível em https://drive.google.com/file/d/1tHnB8xQXerTaY3gD9IlcEsQs_d0jNssW/view.
} 
gamificação e os dispositivos digitais no processo de aprendizagem. $\mathrm{O}$ áudio das entrevistas foi gravado e transcrito posteriormente para análise. Durante a transcrição e apresentação das falas dos sujeitos neste artigo, utilizamos o termo "Entrevistado" ou a vogal "E" concatenada ao número sequencial de 1 a 5 para referenciar os sujeitos, por exemplo, Entrevistado 1 ou E1.

Ressaltamos que o projeto foi submetido, na Plataforma Brasil, à apreciação do Comitê de Ética e Pesquisa institucional sob n ${ }^{\circ}$ 15503519.0.0000.8042 de Certificado de Apresentação de Apreciação Ética (CAAE), obtendo a sua aprovação.

\section{Pistas Encontradas na Pesquisa}

Participaram das entrevistas 5 alunos, sendo 3 do gênero masculino e 2 do gênero feminino, com idades compreendidas entre 17 e 18 anos que vivenciaram a gamificação e os dispositivos digitais no $10^{\circ}$ ano do Curso Profissional do Ensino Secundário com formação em Técnico de Programador de Informática por meio do projeto "Magos da Sabedoria" durante a disciplina de Português. Na Figura 1 estão ilustrados momentos de entrevistas com os sujeitos da pesquisa.

Figura 2 - Registro visual das entrevistas realizadas.

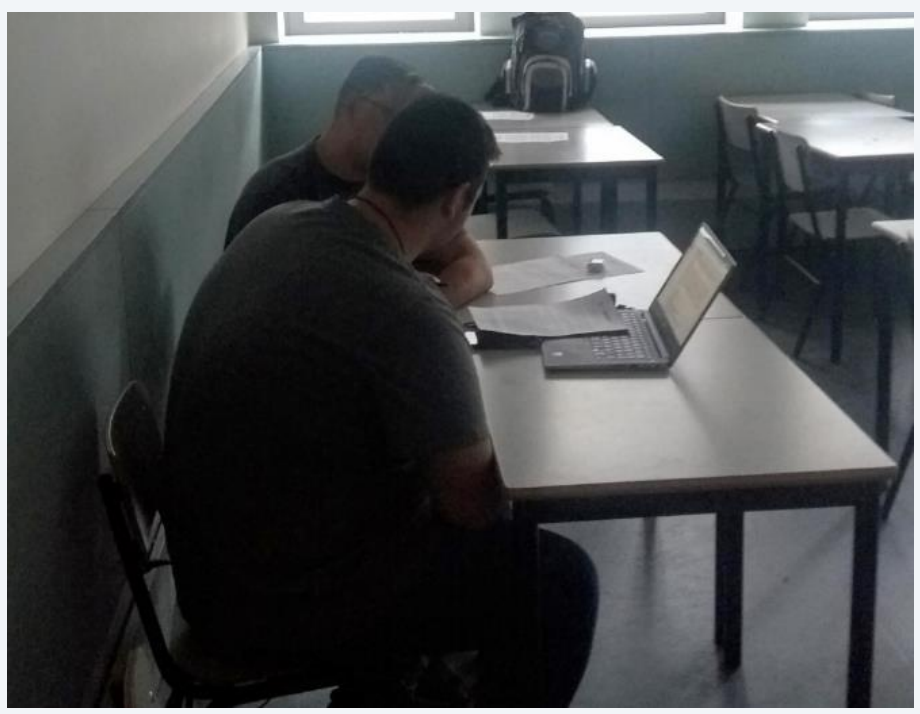

Fonte: Elaborado pelos autores.

Após categorizar o perfil dos alunos, iniciamos as entrevistas perguntando aos participantes se conheciam a gamificação e como eles definiriam tal conceito. Dos 5 entrevistados, 4 (80\%) afirmaram conhecer o termo gamificação e apenas o Entrevistado 2 (20\%) informou desconhecer, conforme apresentado no Quadro 1. 
Quadro 1 - Conhece o termo gamificação? Fale sobre o conceito.

\begin{tabular}{|c|l|}
\hline Sujeito & \multicolumn{1}{c|}{ Fala } \\
\hline E1 & $\begin{array}{l}\text { "Sim. Aqui na escola. Alguns sites e também alguns jogos. O Quizlet que é um jogo que } \\
\text { nós utilizamos para uma pergunta de uma determinada matéria e nós temos que saber em } \\
\text { que momento foi situado. E também fazemos às vezes alguns formulários na internet, } \\
\text { principalmente no Google, quando nós temos que criar alguns formulários nossos sobre a } \\
\text { matéria que nós damos como matemática e português." }\end{array}$ \\
\hline E2 & "Não." \\
\hline E3 & $\begin{array}{l}\text { "Sim. Eu tenho professores que já utilizaram gamificação em suas aulas. O maior ponto } \\
\text { foi na aula de português, onde a professora inovou e criou novos métodos para educação." }\end{array}$ \\
\hline E5 & $\begin{array}{l}\text { "Sim. Nós nas aulas já fizemos jogos educativos, incluindo um Escape Room, que consiste } \\
\text { en termos de desenvolver, não é bem desenvolver, é mais descobrir os passos, decifrá-los }\end{array}$ \\
\hline $\begin{array}{l}\text { "Sim. A gamtar tudo e temos uma espécie de uma chave para sair." } \\
\text { métodos, incentivare tem como objetivo como objetivo a utilização digamos novos nomos assim, nós alunos ficamos mais concentrados, ou seja, } \\
\text { olhar coisas que existem atualmente e introduzir isso para tornar a matéria mais } \\
\text { interessante." }\end{array}$ \\
\hline
\end{tabular}

Fonte: Elaborado pelos autores.

De modo geral, percebemos nas falas dos entrevistados, elencadas no Quadro 1, que eles utilizaram exemplos de situações vivenciadas para definir a gamificação e não demonstraram consenso e precisão sobre a definição do termo. Acreditamos que durante o processo de ensino e aprendizagem é imprescindível a clareza de termos e a consciência da metodologia empregada no aprendizado, principalmente quando tratamos do uso da gamificação. A gamificação utiliza mecânicas, dinâmicas e estéticas inspiradas nos jogos digitais, tornando o limiar entre a gamificação na educação e a aprendizagem baseada em jogos digitais bastante tênue, conforme aponta Moura (2019).

É preciso não confundir gamificação com jogos digitais educativos ou jogos sérios. Na gamificação o aluno não joga um jogo inteiro do início ao fim. Os alunos participam em atividades que incluem elementos motivacionais dos jogos, como por exemplo ganhar pontos, superar um desafio ou receber emblemas pelo bom desempenho nas tarefas. (MOURA, 2019, p. 65)

A partir da escuta sensível às falas dos sujeitos, descritas no Quadro 1, percebemos pistas de como a gamificação e os motivos pedagógicos desta na educação foram entendidos. Para E5, a gamificação é um método para "incentivar" e "atrair" os alunos, deixando-os "mais concentrados" e tornando "a matéria mais interessante". Observamos, nesta fala, termos comumente utilizados para justificar a gamificação na educação, indicando que o aluno entendeu o propósito pedagógico desta no projeto "Magos da Sabedoria". Ademais, a fala do Entrevistado 3 realçou a importância da gamificação neste projeto quando ele afirmou que, dentre as experiências vivenciadas, "O maior ponto foi na aula de português" (E3). 
Com relação a resposta do Entrevistado 2, que inicialmente disse não ter conhecimento sobre a gamificação, ao prosseguir a entrevista, suas falas apontaram a dissociação do termo as práticas pedagógicas vivenciadas, pois, as respostas aos questionamentos posteriores demonstraram que, assim como os demais alunos, ele experenciou a gamificação e os dispositivos digitais no projeto "Magos da Sabedoria". Essa situação reforça a necessidade e importância da clareza e consciência dos alunos sobre as metodologias utilizadas nas salas de aula, visto que eles são os atores principais no processo.

Ao pedir que descrevessem suas experiências sobre a gamificação no processo de aprendizagem, destacando a forma como ela, os elementos de jogos digitais e os dispositivos digitais foram utilizados, os entrevistados emitiram falas que apontaram diferentes estratégias. Em um primeiro instante, as falas não remetiam, claramente, a forma como a gamificação foi empregada, visto que os entrevistados indicaram atividades de criação de sites, de formulários e de jogos educativos por meio de aplicativos como o Kahoot, o Quizlet, o Google Formulário e o Google Sites (vide Quadro 2).

Quadro 2 - Como foi o uso da gamificação no processo de ensino e aprendizagem?

\begin{tabular}{|c|l|}
\hline Sujeito & \multicolumn{1}{c|}{ Fala } \\
\hline E1 & $\begin{array}{l}\text { "Alguns sites e também alguns jogos. O Quizlet que é um jogo que nós utilizamos para } \\
\text { uma pergunta de uma determinada matéria e nós temos que saber em que momento foi } \\
\text { situado. E também fazemos às vezes alguns formulários na internet, principalmente no } \\
\text { Google, quando nós temos que criar alguns nossos formulários sobre a matéria que nós } \\
\text { damos, como matemática e português. Por exemplo, a história de Camões, nós criamos } \\
\text { formulários sobre a história de Camões resumindo e aprendemos mais sobre a história de } \\
\text { Camões. Criamos mais alguns aplicativos para resumimos a matéria." }\end{array}$ \\
\hline E2 & $\begin{array}{l}\text { "Nós programamos, fazemos, jogos através de um computador. Nós aqui na aula de } \\
\text { português, nós utilizamos o Kahoot para continuar a nossa aprendizagem e o Quizlet." }\end{array}$ \\
\hline E3 & $\begin{array}{l}\text { "Eu utilizei a gamificação em um projeto que a professora de português deu sobre criar } \\
\text { sites a partir de uma história de um artista português onde tínhamos que explicar o percurso, } \\
\text { estilo de vida e informações mais a fundo sobre ele." }\end{array}$ \\
\hline E4 & $\begin{array}{l}\text { "Nós nas aulas já fizemos jogos educativos, incluindo um Escape Room, que consistem em } \\
\text { termos de desenvolver, não é bem desenvolver, é mais descobrir os passos, decifrá-los e } \\
\text { no final juntar tudo e temos uma espécie de uma chave para sair. O Kahoot e o Quizlet." }\end{array}$ \\
\hline E5 & $\begin{array}{l}\text { "Temos o Kahoot e o Escape Room e a professora pediu para fazermos um site nosso sobre } \\
\text { os Lusíadas onde nós tínhamos que contar cada passagem, digamos assim, da história." }\end{array}$ \\
\hline
\end{tabular}

Fonte: Elaborado pelos autores.

Entretanto, as falas eram relatos de experiências das atividades gamificadas no projeto "Magos da Sabedoria”. Então, foi necessário analisá-las sobre este olhar e cruzá-las com as mecânicas, ideias e estéticas de jogos digitais presentes no site do projeto, pois, de acordo com Moura (2019), os alunos foram confrontados com diferentes elementos dos jogos, dentre eles, 
elementos de competição, de estrutura, de evolução e de feedback, sendo que "os elementos de estrutura apresentam-se nas missões e nos desafios que expõem os tópicos do programa da disciplina" (MOURA, 2019, p. 68). Assim, foi possível entender que a construção de sites, formulários e jogos (de pergunta e respostas e Escape Room) para o estudo, resumo e revisão de conteúdo, em particular sobre a vida Luís de Camões e a obra "os Lusíadas", eram missões ou desafios estabelecidos no projeto e faziam parte da gamificação.

Para Lucena, Schlemmer e Arruda (2019),

A gamificação pode ser pensada a partir de duas perspectivas: como persuasão, estimulando a competição, sistema de pontuação, a recompensa, premiação etc., o que do ponto de vista da educação reforça uma perspectiva epistemológica empirista e, como construção colaborativa e cooperativa, instigada pelo desafio, pela a descoberta, pelo empoderamento em grupo, o que do ponto de vista da educação nos leva a perspectiva epistemológica interacionista-construtivista-sistêmica. (LUCENA; SCHLEMMER; ARRUDA, 2019, p. 17)

Ao aprofundarmos a pesquisa no site do projeto e refletir sobre as falas dos sujeitos, constatamos a natureza epistemológica interacionista-construtivista-sistêmica do projeto, ao verificar detalhes e outras missões não mencionadas pelos alunos como, por exemplo, publicar uma informação no Twitter; estudar por meio de cartões Quizlet; assistir vídeos no Youtube para fazer sínteses e identificar erros; construir mapas mentais no MindMup ${ }^{5}$, apresentações no Google Slides $^{6}$, exames no Testmoz ${ }^{7}$ e minijogos no Arcade Game Generator ${ }^{8}$; e criar vídeos no Animoto $^{9}$. Diante da diversidade de missões em que os alunos precisavam executar, publicar, estudar, assistir, sintetizar, produzir, criar e construir, ficou evidente que a proposta pedagógica favoreceu para que eles se tornassem atores e autores no processo de aprendizagem e assumissem o protagonismo do seu aprendizado para alcançar o "Certificado de Excelência pelo cumprimento de todas as missões" emitido no site do projeto, outro elemento motivacional empregado por Moura (2019) que explora o reconhecimento social dos alunos para engajá-los nas atividades.

Ademais, acreditamos que a diversidade de dispositivos digitais explorados nas missões motivou os alunos pela novidade do inesperado e da inovação, ao mesmo tempo que favoreceu

\footnotetext{
5 Mindmup é uma aplicação web para criação e compartilhamento de mapas mentais. Disponível em https://www.mindmup.com/.

${ }^{6}$ Google Slides é uma aplicação web para criar, editar e colaborar apresentação no formato de slides. Disponível em https://www.google.com/slides/about/.

${ }^{7}$ Testmoz é uma aplicação web construir e compartilhar testes online. Disponível em para https://testmoz.com/.

8 Arcade Game Generator é um site para criar jogos de pergunta e respostas, inspirado em jogos de arcade. Disponível em http://www.classtools.net/arcade/

${ }^{9}$ Animoto é uma aplicação web para edição de vídeos. Disponível em https://animoto.com/.
} 
a fluência digital e aprimorou capacidade de ideação e adaptação destes às tecnologias porvir, habilidades apontadas como essenciais por Brynjolfsson e Mcafee (2015) e Kelly (2018) para recolocação do indivíduo no mercado de trabalho em um futuro no qual inúmeras profissões e postos de trabalho serão extintos.

O Kahoot e o Quizlet foram os dispositivos digitais e o Escape Room foi a estratégia de gamificação mais mencionados nas entrevistas, logo, aprofundamos o estudo sobre eles, buscando compreender os motivos que levaram a lembrança destes durante as falas dos entrevistados.

O Kahoot é uma interface digital, disponível em web e como aplicativo para dispositivos móveis, para criação de jogos de perguntas e respostas a fim de auxiliar no processo de ensino e aprendizagem. Com ele, é possível avaliar o conhecimento prévio, introduzir novos conceitos, revisar conteúdos, avaliar e acompanhar o aprendizado, obter opiniões dos alunos, bem como favorecer a colaboração, o trabalho em equipe e a comunicação. Os jogos são construídos e jogados, individualmente ou em grupos, de qualquer lugar, a qualquer hora, em seus próprios dispositivos. O Quizlet é também uma interface digital, na versão web e mobile, para busca e criação de material de estudo no formato de cartões e de diagramas (mapas, anatomias, tabelas periódicas etc.). Ele permite jogar minijogos com os conteúdos, construir exames para avaliação do conhecimento e acompanhar o progresso da turma, coletiva ou individualmente. Ambos os dispositivos podem ser utilizados em projetos gamificados como parte de missões e desafios, conforme observamos nos relatos sobre o projeto "Magos da Sabedoria".

O Escape Room é um jogo ou estratégia de gamificação, visto que não há consenso da sua classificação na literatura, em que os jogadores são trancados em uma sala (cenário) e precisam decifrar mistérios, executar provas e superar desafios para encontrar ou obter a chave de saída do local. No contexto educacional, ele é empregado de forma pontual, devido à complexidade do planejamento necessário à sua execução (MOURA, 2018).

Independente da forma como foi gamificada a atividade, é essencial o alinhamento desta à proposta pedagógica da disciplina para proporcionar o resgate do prazer e da ludicidade em realizar as atividades dentro e fora da sala de aula e promover o papel ativo durante o aprendizado. Observamos nas falas dos entrevistados que, durante o projeto "Magos da Sabedoria", as atividades proporcionaram momentos em que os alunos eram atores e também autores no processo de aprendizagem, permitindo-os compreender a importância delas no seu aprendizado, conforme afirma Moura (2019, p. 68), "no desenvolvimento das missões os alunos vão compreendendo que as atividades têm sempre uma finalidade e um sentido pedagógico". 
Possibilitar que os jovens sejam autores de recursos pedagógicos e midiáticos para o próprio aprendizado e dos colegas favorece o seu protagonismo e sua capacidade de autonomia, de ideação, de criatividade, de expressão, de colaboração e de autoria, além de aproximar da forma "de se expressar, de comunicar e de produzir que mistura e remixa diferentes linguagens" (LUCENA, 2016, p. 284) - escrita, oral e hipermídia - que a juventude utiliza, principalmente com a popularização dos dispositivos móveis.

Mas, será que os alunos se sentiram interessados, motivados e engajados durante o processo de aprendizagem? Assumir o papel protagonista de próprio aprendizado exige disciplina, determinação e dedicação durante o processo. Tais características são normalmente observadas nos jovens quando eles jogam. Eles se sentem atraídos pela ludicidade e pela participação voluntária, de modo que o jogador opta por jogar aquele jogo, aquela partida e naquele momento. Já no contexto escolar, especificamente no ensino formal, os professores devem lecionar assuntos de currículos inflexíveis, em curto tempo, maximizando o aprendizado dos alunos, com metodologias que desconsideram as particularidades inerentes aos jovens que vivenciam às culturas digitais devido à resistência na inserção de tecnologias digitais de informação e comunicação nas escolas. Neste sentido, diante da forma como o projeto foi gamificado, buscamos compreender se ele conseguiu atrair a atenção dos alunos; despertou seu interesse na disciplina; influenciou na motivação e no engajamento dos alunos. As falas dos sujeitos apontaram que eles ficaram à vontade durante o aprendizado; se sentiram ativos, atraídos, motivados e engajados no processo; e perceberam a melhora no seu rendimento escolar, conforme Quadro 3.

Quadro 3 - A gamificação influenciou na motivação e no engajamento durante as aulas?

\begin{tabular}{|c|l|}
\hline Sujeito & \multicolumn{1}{c|}{ Fala } \\
\hline E1 & $\begin{array}{l}\text { "Nós nos sentimos bastante ativos e atraídos por essas aplicações e cada dia com mais } \\
\text { vontade de utilizá-los." }\end{array}$ \\
\hline E2 & $\begin{array}{l}\text { "Tem uma melhor aprendizagem, eu acho. Nós aprendemos mais rápido com jogos do que } \\
\text { sendo uma aula teórica." }\end{array}$ \\
\hline E3 & $\begin{array}{l}\text { "Por ser uma coisa nova, isso foi novo para mim, e ao mesmo tempo foi interessante porque } \\
\text { eu nunca tinha tido uma experiência igual a gamificação e posso dizer que esta experiência } \\
\text { que tive foi boa e rendeu com o ensino. Posso dizer que a aprendizagem foi mais fácil } \\
\text { porque os alunos ficaram mais à vontade." }\end{array}$ \\
\hline E4 & $\begin{array}{l}\text { "Eu melhorei muito. No meu caso, eu tirava notas assim, mas com gamificação as minhas } \\
\text { notas melhoraram bastante." } \\
\text { "Eu acho que ajudou e muito, porque muitos melhoraram. No caso, chama mais atenção } \\
\text { dos alunos para a matéria, o que integra mais na ação, por exemplo, no meu curso muitas } \\
\text { pessoas gostam de jogos, ou seja, muitos ficam interessados na matéria porque tem jogos } \\
\text { envolvidos." }\end{array}$ \\
\hline E5 & $\begin{array}{l}\text { "A gamificação ajuda nós alunos ficar mais atentos nas aulas. Na disciplina de português, } \\
\text { quando estamos a preparar, por exemplo, para teste, a professora lança, digamos, um jogo }\end{array}$ \\
\hline
\end{tabular}


O reconhecimento do próprio aluno ao dizer que "minhas notas melhoraram bastante" (E4) e "eu acho que ajudou e muito, porque muitos melhoraram" (E4) mostra que a gamificação e os dispositivos digitais impactaram significativamente na forma de aprender, alcançando resultados que perpassam interesse momentâneo. Para tanto, o uso dos elementos deve ser encarado com cautela e seriedade, pautado em objetivos pedagógicos claros e escolhas que considerem o perfil socio-cultural-econômico dos alunos, pois, sem o devido cuidado, como uma simples forma de divertir os alunos durante aquelas aulas consideradas "chatas", pode gerar resultados insatisfatórios, conforme alertado por Fardo (2013).

Sem um conhecimento aprofundado sobre a gamificação, aplicá-la na educação pode impactar de forma não esperada os processos de ensino e aprendizagem. Pode ainda ser empregada de forma incorreta ou equivocada, reforçando mais ainda alguns problemas presentes no sistema de ensino atual. (FARDO, 2013, p. 4)

Por outro lado, mesmo com a popularização dos dispositivos móveis e as perceptíveis mudanças na forma de agir, interagir, pensar e aprender, muitos professores relutam em utilizálos nas suas práticas pedagógicas por desconhecimento às tecnologias e medo de perder o controle e a autoridade em sala de aula.

[...] muitos professores hesitam em utilizar os recursos tecnológicos dos celulares porque não possuem o conhecimento técnico para tal e temem que os alunos não mais se concentrem no estudo dos conteúdos das disciplinas ministradas. Caso eles permitissem o uso generalizado de tais aparelhos no transcorrer de suas aulas, como poderiam assegurar que os alunos continuariam a prestar atenção em suas explicações? (GOMES; ZUIN, 2017, p. 210)

Esta preocupação em dividir/disputar a atenção na sala de aula é errônea, comum e natural, fruto de falta da formação inicial e continuada e vivência em práticas pedagógicas com as TDIC. Os professores deveriam ter formações para experenciar e se apropriar das tecnologias digitais e móveis a fim de inserir no contexto escolar, pois “o impacto transformador das TDIC na educação só será viável se estiver em confluência com a formação de professores para seu uso educacional, abrangendo todas as suas possibilidades de transformação e emancipação dos sujeitos." (JOAQUIM; PESCE, p. 133). 
Outro aspecto observado na experiência do projeto analisado foi a influência da gamificação e dos dispositivos digitais na comunicação entre professor-aluno e aluno-aluno. Apenas os entrevistados E1, E4 e E5 responderam ao questionamento "A gamificação influenciou na comunicação/interação professor-aluno-aluno?”, conforme Quadro 4.

Quadro 4 - A gamificação influenciou na comunicação/interação professor-aluno-aluno?

\begin{tabular}{|c|l|}
\hline Sujeito & \multicolumn{1}{|c|}{ Fala } \\
\hline E1 & $\begin{array}{l}\text { "Nós temos um portal, um blog quer dizer, que nossa professora criou para cada um dos } \\
\text { anos, } 10^{\circ} \text { e } 11^{\circ} \text { ano, onde nós podemos encontrar vários materiais e isso facilita para } \\
\text { podermos realizar alguns testes." } \\
\text { "Os pontos positivos é que você aprende melhor, interagimos uns com os outros e como eu } \\
\text { estava a dizer a equipe de trabalho em si." }\end{array}$ \\
\hline E4 & $\begin{array}{l}\text { "Eu considero a interação entre os outros, por exemplo, da mesma classe. A interação com } \\
\text { os professores e também o pensamento." } \\
\text { "Nós alunos temos uma tendência a estudar mais para aqueles professores que interagem } \\
\text { mais conosco, logo, a professora ao inserir jogos nós passamos a estudar mais para } \\
\text { professora." }\end{array}$ \\
\hline E5 & $\begin{array}{l}\text { "Acessamos o site de nossa professora constantemente e quando a professora lança vários } \\
\text { vídeos, ela explica a matéria, explica os textos, ela lança as vezes testes e também fala dos } \\
\text { vídeos como já havia referido sobre a matéria." } \\
\text { "A proximidade com os professores. E a explicação de nossa professora em vídeo é como } \\
\text { se estivesse em nosso lar, em casa, explicando a matéria." } \\
\text { "Em trabalhos de grupos que nós fazemos melhora e ajuda ao mesmo tempo, esses projetos } \\
\text { que, neste caso, na aula de português, a professora propõe em trabalho em grupo e com } \\
\text { isso ficamos, conhecemos uns aos outros e conseguimos trabalhar melhor em equipe." }\end{array}$ \\
\hline
\end{tabular}

Fonte: Elaborado pelos autores.

Os entrevistados demonstraram que a gamificação e os dispositivos digitais favoreceram a comunicação entre professor-aluno e aluno-aluno. Na relação professor-aluno, o uso do blog, de jogos e de videoaulas foram apontados como os meios de comunicação que aproximaram os sujeitos. Os alunos reconheceram a importância do uso destes dispositivos digitais no aprendizado dentro e fora da sala de aula, permitindo que eles aprendessem os assuntos em aulas que estavam ausentes ou revisassem os conteúdos para sanar dúvidas e se preparassem para os exames, a qualquer hora e em qualquer lugar, quando afirmam que no blog "nós podemos encontrar vários materiais e isso facilita para podermos realizar alguns testes" (E1) e “a explicação de nossa professora em vídeo é como se estivesse em nosso lar, em casa, explicando a matéria" (E5). Os sujeitos também destacaram melhorias na comunicação alunoaluno proporcionada por missões que incentivaram o trabalho em equipe, entretanto, não deixaram claro quais dispositivos digitais foram utilizados. 
Quadro 5 - O uso de dispositivos digitais em sala de aula.

\begin{tabular}{|c|l|}
\hline Sujeito & \multicolumn{1}{c|}{ Fala } \\
\hline E1 & $\begin{array}{l}\text { "Alguns alunos conseguiam se safar mais fazendo um trabalho, teste no telemóvel, do que } \\
\text { no papel, então a professora lançava muitos desafios em realizar vários trabalhos do que } \\
\text { ser no papel e os alunos diziam sempre que preferiam que a avaliação fosse no telemóvel } \\
\text { do que no papel porque no papel é um bocadinho mais difícil por causa do vocabulário que } \\
\text { alguns têm dificuldades, então a professora usava várias aplicações, para que tivéssemos } \\
\text { vários trabalhos e lançava bastante desafios e nós tínhamos, claro que a professora ajudava, } \\
\text { era desafiado. Nós procuramos várias aplicações para fazermos nosso trabalho, usando } \\
\text { word, excel, tanto faz, no Quizlet ou formulários, fazer trabalhos de resumos do que demos } \\
\text { na aula, dos textos lidos etc." }\end{array}$ \\
\hline E3 & $\begin{array}{l}\text { "Os vídeos informativos, os jogos que é bem intuitivo e ensinam o que é proposto." } \\
\text { "Foram utilizados computadores e fichas em folha." }\end{array}$ \\
\hline E5 & $\begin{array}{l}\text { "A gamificação sobre o uso de tecnologias mundanas, como telemóvel, é bastante útil em } \\
\text { sala de aula." } \\
\text { "O computador, nosso telemóvel e a escola disponibilizou o tablet." } \\
\text { "Bem, o que mais nos motivou a estar atento às aulas foi o uso do telemóvel. Hoje mesmo } \\
\text { sem autorização, algumas pessoas tentam usar dentro das salas e com o uso do telemóvel } \\
\text { ficamos bem mais amarrados no estudo do que está sempre a escrever, depois chegamos } \\
\text { em casa e depois esquecemos de passar alguma coisa, assim com o telemóvel a } \\
\text { possibilidade de perdermos alguma afirmação é impossível. E se esquecemos algumas } \\
\text { coisas, o nosso colega ao lado, é só mandarmos o texto que ele tinha escrito." }\end{array}$ \\
\hline
\end{tabular}

Fonte: Elaborado pelos autores.

As falas dos sujeitos E1 e E5 são retratos da familiaridade dos jovens com os dispositivos digitais e móveis. O uso de aplicativos em smartphones, chamados pelos entrevistados de "telemóvel", é uma realidade da juventude imersa nas culturas digitais e eles aprenderam a explorá-los para superar as dificuldades e as limitações enfrentadas no cotidiano. Os sujeitos demonstram que a falta de vocabulário na escrita em punho com papel e lápis é facilmente superada com o uso de editores de texto ou aplicativos de troca de mensagens em dispositivos digitais, uma vez que eles sugerem automaticamente palavras semelhantes e a correção de erros ortográficos; a fidelidade do conteúdo apresentado pelo professor em sala de aula é garantida pelo áudio capturado durante a aula, que pode ser repassado ao colega, se necessário; textos, desenhos, mapas ou jogos construídos dentro e fora da sala de aula podem ser compartilhados sem custo, a qualquer hora e em qualquer lugar com o colega. As potencialidades das TDIC na educação são percebidas, identificadas e exploradas pelos jovens imersos nas culturas digitais.

Com as culturas digitais, as pessoas produzem, socializam culturas, sonhos, desejos, textos, imagens, sons, e a combinação destes. Vivem, constroem e reconstroem suas vidas e relações em seus cotidianos, participam da vida política, econômica, cultural e participam em instituições públicas e privadas. Influenciam e são influenciados pelas mídias em sinergia entre o mundo 
presencial e digital em múltiplos tempos e espaços. (LUCENA; OLIVEIRA, 2014, p. 38)

É essencial que tenhamos consciência da influência das culturas digitais no cotidiano dos jovens e que os atores sociais insiram na escola elementos desta cultura para se aproximar da realidade destes. Entretanto, o que ainda se observa são escolas e professores que não permitem a inserção das tecnologias digitais e móveis em sala de aula, diante de um discurso de que distrai o aluno e/ou que o professor perde a autoridade em sala de aula ao disputar a atenção com os dispositivos móveis, embora, "hoje, mesmo sem autorização, algumas pessoas tentam usar dentro das salas [...]" (E5). É interessante observar, nas falas de E1 e E5, que o "telemóvel” já se faz presente nas salas de aula, com consentimento ou não, de modo transparente ou escondidos dos professores e gestores da escola.

Por isso que, por compreender as potencialidades das TDIC no âmbito escolar, acreditamos que elas devem ser permitidas, avaliadas, monitoradas e alinhadas ao projeto pedagógico, assim como qualquer outro recurso em uso na sala de aula. Se por um lado o corretor ortográfico dos editores de texto e dos aplicativos de troca de mensagens podem facilitar e agilizar a escrita dos jovens que precisam se comunicar formalmente diante da sociedade, por outro, o uso indiscriminado de tais recursos podem ocasionar/reforçar problemas na escrita formal dos jovens. Para tanto, "o professor precisa conhecer, para além das noções básicas, as potencialidades e possibilidades das tecnologias móveis e redes sociais, para poder criar ou cocriar com seus alunos práticas que mais se adéquem a realidade da turma e da escola" (LUCENA e VALE, 2014, p. 166), pois, se devidamente empregadas, as TDIC favorecem o processo de aprendizagem. De modo que, um simples editor de texto pode auxiliar o aluno no aprendizado da escrita, enriquecer o seu vocabulário com sinônimos, promover a colaboração e o trabalho em equipe com os colegas, além de motivá-los por envolver elementos das culturas digitais.

\section{Considerações Finais}

A gamificação tem ganhado notoriedade na educação, na contemporaneidade, como estratégia pedagógica que busca na ludicidade e no uso de elementos dos jogos digitais meios para se aproximar do cotidiano de jovens imersos nas culturas digitais e resgatar o prazer em aprender dentro e fora da sala de aula.

Em meio a popularidade da gamificação na educação, surgem preocupações e cuidados a serem tomados com o intuito de evitar que os resultados obtidos com ela sejam divergentes 
dos objetivos pedagógicos esperados. É essencial que, primeiramente, os professores saibam as potencialidades e limitações desta estratégia, compreendam as dinâmicas, mecânicas e estéticas dos jogos digitais, conheçam o perfil sócio-cultural-econômico dos seus alunos e tenham vivências e experiências com a gamificação e as tecnologias digitais e móveis durante as formações inicias e continuadas. Além desses cuidados, é importante empregar a gamificação com parcimônia, escolhendo adequadamente os elementos dos jogos digitais empregados, partindo do perfil dos alunos e suas experiências, por meio de abordagens que valorizem a colaboração, a comunicação, a cocriação, a autoria e o processo formativo, em uma “[...] perspectiva epistemológica interacionista-construtivista-sistêmica"

(LUCENA; SCHLEMMER; ARRUDA, 2019, p. 17), e não simplesmente competições em que “[...] o outro é sempre, ou melhor, ou pior que você, nunca o diferente com quem se pode aprender" (SCHLEMMER, 2016, p. 115).

Neste sentido, nas falas dos sujeitos entrevistados que participaram do projeto "Magos da Sabedoria", nas aulas de Português durante sua formação em Técnico de Programador de Informática, emergiram pistas importantes de como a prática pedagógica gamificada com tecnologias digitais e móveis, em um processo de aprendizagem, pode potencializar o aprendizado, tornando-o mais lúdico, atraente e significativo, ao tempo em que são desenvolvidas habilidades e competências essenciais aos indivíduos para o século XXI como pensamento crítico, resolução de problemas, criatividade, comunicação, colaboração e fluência digital. Para isso, os atores sociais que fazem o contexto escolar devem permitir as TDIC na sala de aula, tornando a inserção de "[...] tecnologias mundanas, como telemóvel, [...]" (E5), presentes no cotidiano dos jovens, uma oportunidade de aprendizagem e aproximação das culturas digitais. É importante, ainda, proporcionar práticas com diferentes mídias digitais (imagens, desenhos, mapas, jogos, áudios e vídeos) e múltiplos dispositivos digitais, possibilitando a colaboração, a criatividade, a autoria e o aprender com o outro; além disso, o professor deve mediar e se fazer presente no processo, sendo acessível e disponível aos alunos.

\section{Agradecimentos}

Agradecemos a Reitoria do Instituto Federal de Sergipe que, a partir do Edital N$^{\circ}$ 01/2018/REITORIA/IFS, proporcionou e financiou a mobilidade internacional acadêmica em Portugal, no Instituto Superior de Engenharia do Porto (ISEP) do Instituto Politécnico do Porto (IPP). 
Agradecemos a Prof ${ }^{a}$ Paula Escudeiro e ao Prof ${ }^{o}$. Carlos Ramos, coordenadores do Graphics, Interaction and Learning Technologies Group do ISEP/IPP, pela recepção e apoio durante a mobilidade internacional acadêmica e a Escola Secundária de Carlos Amarante, em Braga, Portugal, na pessoa da Prof ${ }^{a}$ Adelina Moura, pela atenção e apoio durante o estudo realizado, bem como os alunos que participaram das entrevistas voluntariamente.

Por fim, expressamos nossa gratidão ao Prof $^{\circ}$ Mário André e Prof ${ }^{\circ}$ Wlamir Soares, ambos do IFS, que compartilharam os momentos da mobilidade e auxiliaram nas entrevistas com os sujeitos da pesquisa.

\section{REFERÊNCIAS}

ALVES, Lynn Rosalina Gama. A cultura lúdica e cultura digital: interfaces possíveis. Revista EntreIdeias, Salvador, v. 3, n. 2, p. 101-112, 2014. Disponível em:

<https://portalseer.ufba.br/index.php/entreideias/article/view/7873>. Acesso em: 18 jul. 2020. doi: http://dx.doi.org/10.9771/2317-1219rf.v3i2.7873

BRYNJOLFSSON, Erik; MCAFEE, Andrew. A segunda era das máquinas: trabalho, progresso e prosperidade em uma época de tecnologias brilhantes. Rio de Janeiro, RJ: Alta Books, 2015.

CASTELLS, Manuel. A sociedade em rede. São Paulo: Paz e Terra, v. 1, 2002.

CSIKSZENTMIHALYI, Mihaly. The flow experience and its significance for human psychologt. In: CSIKSZENTMIHALYI, Mihalyi; CSIKSZENTMIHALYI, Isabella Selega. Optimal experience: Psychological studies of flow in consciousness. Cambridge: Cambridge University Press, 1988. p. 15-35.

GOMES, Dulcinéia Oliveira.; ZUIN, Antônio Álvaro Soares. A cultura digital, as TIC e a reconfiguração da relação professor-aluno em Rio Verde-GO. Práxis Educacional (Online), v. 13, p. 198-213, 2017. Disponível em:

<http://periodicos2.uesb.br/index.php/praxis/article/view/960>. Acesso em: 18 jul. 2020. doi: https://doi.org/10.22481/praxis.v13i25.960

FARDO, Marcelo Luis A gamificação aplicada em ambientes de aprendizagem. RENOTE, v. 11, n. 1, p. 1-9, 2013. Disponível em: <https://seer.ufrgs.br/renote/article/view/41629>. Acesso em: 18 jul. 2020. doi: https://doi.org/10.22456/1679-1916.41629

JOAQUIM, Bruno dos Santos; PESCE, Lucila. O uso (crítico) das tecnologias digitais da informação e da comunicação na educação (não compensatória) de jovens e adultos. Práxis Educacional, [S.1.], v. 14, n. 29, p. 126-142, ago. 2018. ISSN 2178-2679. Disponível em: <http://periodicos2.uesb.br/index.php/praxis/article/view/4102>. Acesso em: 18 jul. 2020. doi: https://doi.org/10.22481/praxis.v14i29.4102. 
KAPP, Karl M. The Gamification of Learning and Instruction: Game-based Methods and Strategies for Training and Education. John Wiley \& Sons, 2012.

KELLY, Kevin. Inevitável: as 12 forças tecnológicas que mudarão nosso mundo. Alta Books Editora, 2018.

LUCENA, Simone. Culturas digitais e tecnologias móveis na educação. Educar em Revista, n. 59, p. 277-290, 2016. Disponível em: <

https://www.scielo.br/scielo.php?script=sci_arttext\&pid=S0104-

40602016000100277\&lng=pt\&tlng=pt >. Acesso em: 18 jul. 2020. doi:

https://doi.org/10.1590/0104-4060.43689.

LUCENA, Simone Ferreira; OLIVEIRA, Arlene A. D.; SANTOS JÚNIOR, Gilson Pereira dos. A WEB 2.0 e os Softwares sociais outros espaçostempos multirreferencias de formação na iniciação à docência. In: Cristiane Porto, Kaio Eduardo Oliveira e Alexandre Chagas. (Org.). WhatsApp e Educação: entre mensagens, imagens e sons. Edufba, 2017, p. 9297.

LUCENA, Simone; OLIVEIRA, José Mario Aleluia. Culturas digitais na educação do Século XXI. Revista Tempos e Espaços em Educação, p. 35-44, 30 dez. 2014. Disponível em: <https://seer.ufs.br/index.php/revtee/article/view/3449>. Acesso em: 18 jul. 2020. doi: https://doi.org/10.20952/revtee.v0i0.3449.

LUCENA, S.; SCHLEMMER, E.; ARRUDA, E. P. A cidade como espaço de aprendizagem: educação e mobilidade na formação docente. Revista Tempos e Espaços em Educação, v. 11, n. 01, p. 11-24, 13 jun. 2019. Disponível em:

<https://seer.ufs.br/index.php/revtee/article/view/10214>. Acesso em: 18 jul. 2020. doi: https://doi.org/10.20952/revtee.v11i01.10214.

LUCENA, Simone; VALE, Lucas Cerqueira do. Redes sociais na educação: um espaço de aprendizagem e interação é possível. Cultura digital, jogos eletrônicos e educação. Salvador: EDUFBA, p. 161-177, 2014.

PRESKY, Marc. Não me atrapalhe, mãe - Eu estou aprendendo! como videogames estão preparando nossos filhos para o sucesso no século XXI: e como você pode ajudar!. São Paulo: Phorte Editora, p. 320, 2010.

MARTINS, C.; GIRAFFA, L. M. M. Possibilidades de ressignificações nas práticas pedagógicas emergentes da gamificação. ETD - Educação Temática Digital, v. 20, n. 1, p. 5-26, 15 jan. 2018. Disponível em:

<https://periodicos.sbu.unicamp.br/ojs/index.php/etd/article/view/8645976>. Acesso em: 18 jul. 2020. doi: https://doi.org/10.20396/etd.v20i1.8645976.

MOURA, Adelina. Uma estratégia de gamificação para envolver os alunos na aprendizagem de obras literárias. In: Dias, Paulo; Moreira, Darlinda; Quintas-Mendes, António (Coord.). Inovar para a qualidade na educação digital. Universidade Aberta, p. 63-76, 2019. ISBN 978-972-674-839-7. Disponível em: <http://hdl.handle.net/10400.2/8100>. Acesso em: 18 jul. 2020. 
MOURA, Adelina. Escape Room Educativo: os alunos como produtores criativos. In Afonso, Maria Elisete Conde P.; Ramos, António Luís (Org.). Livro de Atas - 2018 do III Encontro de Boas Práticas Educativas, CFAE Bragança Norte, 2018, p. 117-123. Disponível em: <http://www.cfaebn.pt/3ebpe/livrodeatas3ebpe.pdf >. Acesso em: 18 jul. 2020.

PETRY, Luís Carlos. O conceito ontológico de jogo. Jogos digitais e aprendizagem: fundamentos para uma prática baseada em evidências. Campinas, SP: Papirus, p. 17-42, 2016.

SCHLEMMER, Eliane; LOPES, Daniel de Queiroz. Avaliação da aprendizagem em processos gamificados: desafios para apropriação do método cartográfico. Jogos digitais e aprendizagem. Campinas, Papirus Editora, v. 1, p. 179-208, 2016.

SCHLEMMER, Eliane. Games e gamificação: uma alternativa aos modelos de ead. Revista Iberoamericana de Educación a Distancia (RIED), Asociación Iberoamericana de Educación Superior a Distancia, V. 19, N. 2, 2016. Disponível em: <http://revistas.uned.es/index.php/ried/article/view/15731>. Acesso em: 18 jul. 2020. doi: https://doi.org/10.5944/ried.19.2.15731.

SENA, Samara de; SCHMIEGELOW, Sarah Schmithausen; PRADO, Gladys M. do; DE SOUSA, Richard Perassi Luiz de; FIALHO, Francisco Antonio Pereira. Aprendizagem baseada em jogos digitais: a contribuição dos jogos epistêmicos na geração de novos conhecimentos. Revista Novas Tecnologias na Educação (RENOTE), v. 14, n. 1, 2016. Disponível em: <https://seer.ufrgs.br/renote/article/view/67323>. Acesso em: 18 jul. 2020. doi: https://doi.org/10.22456/1679-1916.67323.

\section{SOBRE OS AUTORES:}

\section{Gilson Pereira dos Santos Júnior}

Doutorando em Educação pelo Programa de Pós-graduação em Educação da Universidade Federal de Sergipe (PPGEd/UFS) - Brasil; Professor Efetivo do Instituto Federal de Sergipe (IFS) - Brasil; Membro do Grupo de Pesquisa em Educação e Culturas Digitais (ECult/UFS/CNPq) e membro do Grupo de Pesquisa no Desenvolvimento de Ferramentas Computacionais e Estratégias Educacionais (GRUFEE/IFS/CNPq). E-mail: gilson.junior@academico.ifs.edu.br

iD http://orcid.org/0000-0002-7545-714X

\section{Paula Escudeiro}

Doutora em Informática, na especialidade de Sistemas e Tecnologias da Informação na Educação pelo Instituto Politécnico do Porto (IPP) - Portugal; Professora Adjunto do Instituto Superior de Engenharia do Porto do Instituto Politécnico do Porto (ISEP/IPP), no Departamento de Engenharia Informática - Portugal; Diretora de curso da Pós Graduação em Tecnologias e Informática Aplicadas à Educação; Diretora do grupo de investigação Games, Interaction and Learning Technologies (GILT). E-mail: pmo@isep.ipp.pt.

\section{iD http://orcid.org/0000-0003-3900-4386}




\section{Adelina Moura}

Doutora em Ciências da Educação, na especialidade de Tecnologia Educativa, na Universidade do Minho - Portugal; Professora do ensino básico e secundário, tutora de cursos de formação a distância do Camões - Instituto da Cooperação e da Língua - e formadora da formação contínua de professores, em didáticas específicas (Português e Francês) e tecnologia educativa Portugal; Membro do grupo de investigação Games, Interaction and Learning Technologies (GILT) do Instituto Superior de Engenharia do Porto (ISEP), Portugal, e membro do grupo de investigação Laboratório de Tecnologia Educativa(LabTE), da Universidade de Coimbra, Portugal. E-mail: adelina8@gmail.com

iD http://orcid.org/0000-0002-5661-5915

\section{Simone Lucena}

Pós-doutora em Educação pelo Programa de Pós-Graduação em Educação da Universidade do Estado do Rio de Janeiro (ProPEd/UERJ) e Doutora em Educação pela Universidade Federal da Bahia (UFBA); Professora do Departamento de Educação da Universidade Federal de Sergipe (UFS), Campus Prof. Alberto Carvalho, e Professora permanente do Programa de Pósgraduação em Educação da Universidade Federal de Sergipe (PPGEd/UFS); Líder do Grupo de Pesquisa em Educação e Culturas Digitais (ECult/UFS/CNPq). E-mail: sissilucena@ gmail.com (iD) http://orcid.org/0000-0003-1636-7707 